\title{
A Ku-band SIW Six-port
}

\author{
GanSiang Tan ${ }^{1}$, Siti Zuraidah Ibrahim ${ }^{2}$, Mohd Nazri A. Karim ${ }^{3}$, Aliya A. Dewani ${ }^{4}$, \\ Mohammad Shahrazel Razalli ${ }^{5}$ \\ 1,2,5 Advanced Communication Engineering (ACE) Centre of Excellence, \\ School of Computer \& Communication Engineering, Universiti Malaysia Perlis, Malaysia \\ ${ }^{3}$ Department of Electronic Engineering Technology, Faculty of Engineering Technology, \\ Universiti Malaysia Perlis, Malaysia \\ ${ }^{4}$ Center for Wireless Monitoring and Applications, School of Electrical Engineering, Griffith University, Australia
}

\begin{tabular}{l} 
Article Info \\
\hline Article history: \\
Received Jan 10, 2019 \\
Revised May 1, 2019 \\
Accepted Jul 1, 2019 \\
\hline
\end{tabular}

\section{Keywords:}

Coupler

Ku-band

Power divider

Six-port

Substrate integrated waveguide

\begin{abstract}
This paper shows a compact fully integrated six-port Substrate Integrated Waveguide (SIW) operating at Ku-Band frequency range. The SIW six-port is formed by combining two SIW power dividers and two SIW couplers, having the benefit of no additional termination is required as this topology has no excessive port. To achieve the optimized design of the six-port, both of the key components; power divider and coupler are primarily designed, fabricated, and measured individually. Y-junction topology is employed on the power divider structure to achieve a compact size. In turn, the coupling coefficient of the two output ports of the SIW coupler are improved by shifting the position of a row of several vias located at the side wall center closer to the side wall. The simulated six port performance provides an advantage of wide bandwidth within Ku-Band across 13 to 17 $\mathrm{GHz}$ with a return loss better than $12 \mathrm{~dB}$ and transmission coefficient of $7 \pm 1.5 \mathrm{~dB}$. The simulated and measured results show good agreement thus validating the prototype. The SIW six-port can find its application in designing a six-port.
\end{abstract}

Copyright () 2020 Institute of Advanced Engineering and Science. All rights reserved.

\section{Corresponding Author:}

Siti Zuraidah Ibrahim,

School of Computer \& Communication Engineering,

Universiti Malaysia Perlis,

Perlis, Malaysia.

Email: sitizuraidah@unimap.edu.my

\section{INTRODUCTION}

The common radar based sensor faces design challenges at high frequency. The six-port interferometer proposed for short range radar based system has shown several advantages compared to the traditional device [1-2]. The six-port interferometer has the advantage of a lower complexity design process at any operating frequency with a wider bandwidth because the structure is constructed by passive components [3].

Generally, the six-port interferometer is formed by the interconnection of power dividers, couplers, and phase shifters [4-5]. Compared to the traditional coaxial cavities or microstrip technique, SIW is known to take advantages of both waveguide and microstrip structures, such as low loss, high power capacity, low cost and easy to integrate in the planar circuit [6-8]. At high operating frequency as Ku-band, the use of SIW is a better choice to design a six-port structure compared to the microstrip technique because the loss contributed by the conductor is low in SIW since the signal is travelling inside the substrate [9]. Unlike in microstrip structure, some of the electric fields is propagating in the air; increasing the losses as the frequency increasing. 
There are some six-port SIW works that are available in the open literature. For instance, the SIW six-port work was successfully demonstrated in [10], employing a dual-layered technique to achieve a compact dimension. Despite its excellent performance, the fabrication of the multi-layer SIW technology is somewhat sensitive, the presence of air-gaps between the layers and the misalignment of the different layers that could cause a degradation in the measured performance of the fabricated device.

Next, a single layer SIW six-port device was presented in [11] but the demonstration is limited to the simulation. In [12-13], the proposed single layer SIW six-port structures were verified experimentally, however, the configuration of the SIW six-port device has more than six ports; seven- or eight ports, in which the unused ports should be terminated by appropriate loads.

Therefore, a single layer SIW six-port junction working in Ku-band is presented in this paper. This work is motivated by the presented single layer SIW six-port device operating at K-Band in [14] that proposes six-port topology with no excessive port. In this paper, different configuration of coupler is applied in the six-port design to obtain a flat response of the transmission coefficient and the phase difference of the output ports across the Ku-band frequency range. As the key components of the six-port device are the power dividers and couplers, the design of each component is presented in detail in the following sub-section. All the components including the final six-port junction are constructed on the RO4003C substrate, having the dielectric constant, $\varepsilon_{r}$ of 3.38 and the thickness, $h$ of $0.508 \mathrm{~mm}$.

\section{RESEARCH METHOD}

The chosen schematic topology of the proposed SIW six-port is shown in Figure 1. The six-port junction presented in this paper is constructed by two power dividers, two hybrid couplers and $\pm 45^{\circ}$ phase shifters. As demonstrated in [14], this topology is compact in size and does not require any external connecting terminals like the traditional six-ports presented in [12-13].

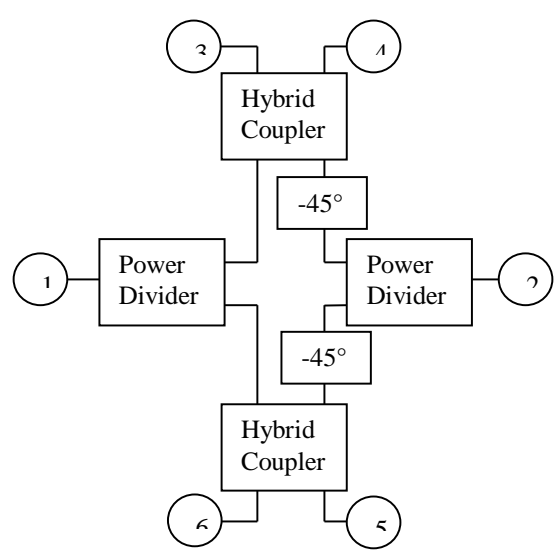

Figure 1. Topology of the six-port

As per the design modelling of SIW given in [15], the corresponding resonant frequency, $f_{c(T E 10)}$ for SIW is used to determine the width of SIW, $W_{\text {eff. }}$ The width of SIW power divider and SIW coupler, $W_{\text {eff }}$ is determined by the mathematical expression (1) and (2):

$$
\begin{aligned}
& f_{c(T E 10)}=\frac{c}{2 \sqrt{\varepsilon_{r}}} \cdot\left(W-\frac{d^{2}}{0.95 \cdot p}\right)^{-1} \\
& W_{\text {eff }}=W-\frac{d^{2}}{0.95 \cdot p}
\end{aligned}
$$

where $c$ is the speed of light, $\varepsilon_{r}$ is the dielectric constant, $W$ is the width of waveguide port, $d$ is the via holes diameter and $p$ is the distance between via holes (centre to centre). In order to achieve an excellent performance of the proposed SIW, a few design rules regarding the via holes, as written in expression (3) to (5) need to be followed [16-17]. 


$$
\begin{aligned}
& \frac{p}{\lambda_{c}}<0.25 \\
& d<\frac{\lambda_{g}}{5} \\
& d<p<2 d
\end{aligned}
$$

where $\lambda_{c}$ is the wavelength of the cutoff frequency, $f_{c(T E I O)}$ and $\lambda_{g}$ guided wavelength of the standard operating frequency.

The SIW power divider is designed based on Y-junction topology[18], where the details design guidelines shown in [19]. The length of $l_{l}$ and $l_{3}$ is set to be enough to perform as the transmission line in SIW mode. The length of $l_{2}$ is optimized to obtain low reflection coefficient $S_{11}$ and transmission coefficients $\mathrm{S}_{21}$ and $\mathrm{S}_{31}$ close to $-3 \mathrm{~dB}$.

For SIW coupler, the electrical coupling strength is achieved by coupling two SIW lines with similar dimensions via a suitable aperture. Compared to the traditional SIW couplers [20-24], the presented coupler configuration in this paper is modified where the position of a row of several vias at the centre with a length, $l_{p}$ is shifted by the parameter $c_{a}$, closer to the side walls. This will gives a wider width at the centre of coupler structure between two rows of the parallel vias. As a result, the amplitude imbalance is reduced, giving a more flat response of the coupling coefficient. The length of $l_{l}$ and $l_{3}$ is set to be enough to perform as the transmission line in SIW mode. The length of $l_{2}$ is optimized to obtain low reflection coefficient $\mathrm{S}_{11}$, low isolation coefficient $\mathrm{S}_{41}$ and transmission coefficients $\mathrm{S}_{21}$ and $\mathrm{S}_{31}$ close to $-3 \mathrm{~dB}$. The length of $l_{2}$ managed to obtain the required performance of $S_{11}$ and $S_{41}$ but the $S_{31}$ is larger than $S_{21}$. The $l_{p}$ and $c_{a}$ is optimized to adjust the power division between $S_{21}$ and $S_{31}$ to be possibly equal. Both increase of $l_{p}$ and $c_{a}$ has increased the $S_{21}$ but decrease the $S_{31}$ performance. As a result, the $S_{21}$ and $S_{31}$ have almost equal power division. Optimization has been done for both SIW power divider and SIW coupler using the electromagnetic simulation tool and the parameters values are shown in Figure 2.

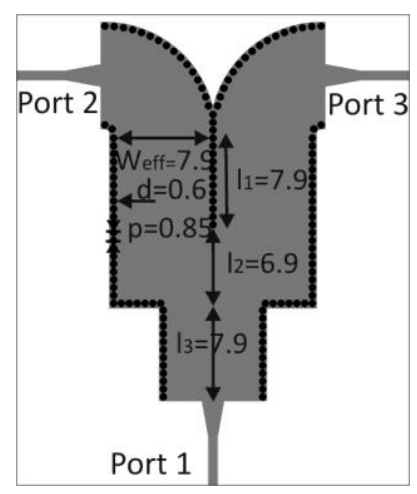

(a)

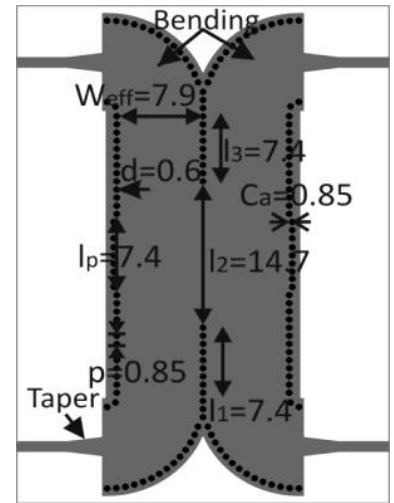

(b)

Figure 2. Geometric configuration and the parameters of (a) SIW power divider and (b) SIW coupler in mm

The SIW six-port layout is shown in Figure 3. As shown in Figure 3, each bend is designed to connect SIW power divider and SIW coupler. The bending line width is set to be similar to the $W_{\text {eff. }}$. The bending has cause some shifting in the operating frequency and introduces little insertion loss. The bending is first designed on SIW power divider and SIW coupler before combined to form SIW six-port. The designed six-port should obtain low reflection coefficient $S_{11}$ and $S_{22}$, and also good isolation $S_{21}$. The transmission $S_{31}$ to $S_{61}$ and $S_{32}$ to $S_{62}$ should be close to $-6 \mathrm{~dB}$. Since the gaps between port 3 and port 4 , and also port 5 and port 6 do not have wide gaps, the connection between the connectors during measurement might be a problem. Therefore, bends are designed for all the output ports to solve this potential problem occurs. The taper is added to improve the matching between the transition SIW to the microstrip line. The initial width is determined first based on [25] and the length of the taper is optimized using a electromagnetic simulation tool to obtain low reflection coefficient and minimize the insertion loss at each port. The extension of the microstrip line is done on port 3, port 4, port 5 and port 6 for easy board cutting 
process since the PCB board cutting machine available can only perform the direct straight cut. The $-45^{\circ}$ and $45^{\circ}$ phase different is performed by shifting the SIW power divider at port 2 towards the SIW coupler at the left hand side. This results in a reduction of SIW transmission line on one side $\left(-45^{\circ}\right.$ phase shift) and addition of SIW transmission line on the other side ( $45^{\circ}$ phase shift) of the SIW coupler to form the SIW six-port. The optimization is done by using the electromagnetic simulation tool to obtain the phase different between port 3 and port 4 , and also port 5 and port 6 close to $90^{\circ}$

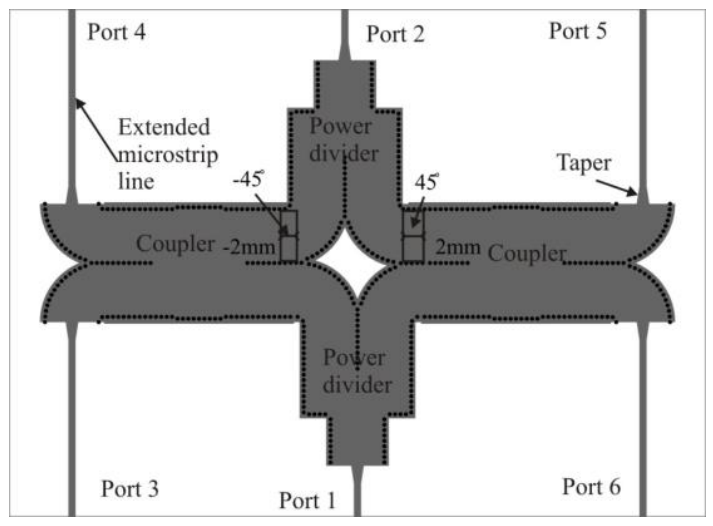

Figure 3. SIW six-port structure highlighting the phase shifts produced due to the addition of transmission lines

\section{RESULTS AND ANALYSIS}

This section provides the analysis of coupler performance in terms of S-parameters such as reflected coefficient, transmission coefficient and the phase differences between the output ports. Based on the optimized design parameters obtained in the previous sections, the structure was simulated and then fabricated to validate the proposed design, as shown in Figure 4. The fabricated prototype of SIW power divider, coupler and six-port are measured using Agilent vector network analyzer E8362B. The simulation and measurement results are discussed in the following sections.

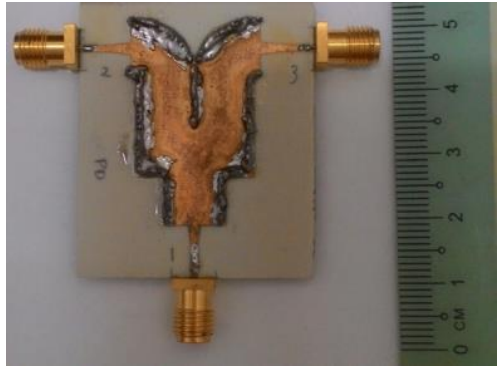

(a)

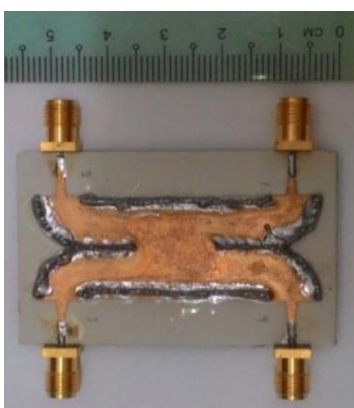

(b)

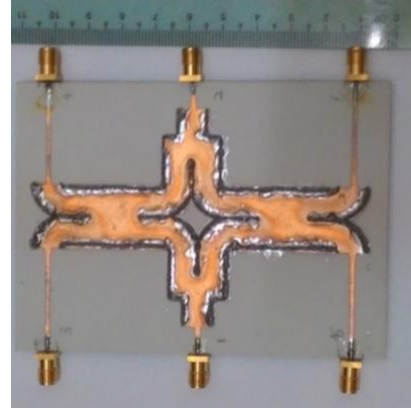

(c)

Figure 4. Photograph of the fabricated (a) SIW power divider, (b) SIW hybrid coupler, (c) SIW six-port

\subsection{Simulation and Measurement Results of SIW Power Divider}

The comparison between the simulation and measurement results of the SIW power divider is shown in Figure 5. As depicted in Figure 5(a), the simulated return loss is better than 15 dB over 13 to 17 $\mathrm{GHz}$ while the measured return loss is better than $9 \mathrm{~dB}$ within the same frequency range. The simulated $\mathrm{S}_{21}$ shown in Figure 5(b) demonstrate a flat response of the output power division with $3.5 \pm 0.1 \mathrm{~dB}$ can be observed across the intended frequency range from 13 to $17 \mathrm{GHz}$. The measured result of $S_{21}$ is $5 \pm 1 \mathrm{~dB}$ across the same frequency range. The degradation of the fabricated prototypes performance might be contributed by the leakage of the propagating signal through the vias due to imperfect conduction of vias holes. 


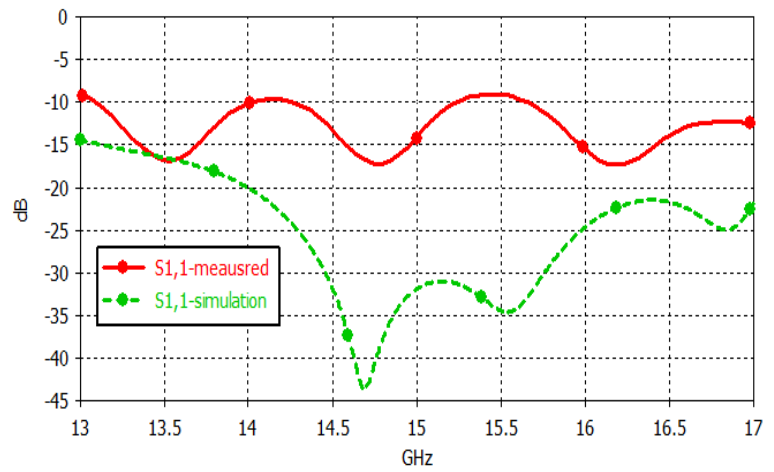

(a)

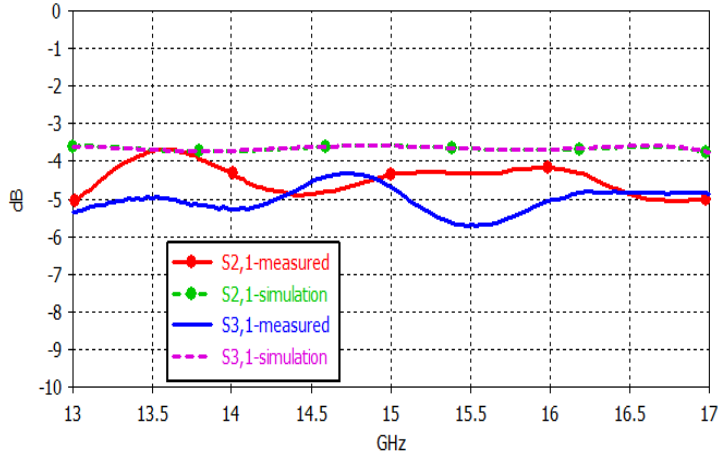

(b)

Figure 5. Comparison between simulation and measurement results of SIW power divider (a) $S_{11}$, (b) $S_{21}, S_{31}$.

\subsection{Simulation and Measurement Results of SIW Hybrid Coupler}

The comparison between the simulation and measurement results of designed SIW coupler is shown in Figure 6. The simulated and measured $S_{11}$ and $S_{41}$ is better than $15 \mathrm{~dB}$ across 13 to $16.8 \mathrm{GHz}$. The simulated $S_{21}$ is approximately $3.8 \pm 0.5 \mathrm{~dB}$ while the measured result is approximately $4.5 \pm 0.5 \mathrm{~dB}$ within the operating frequency of $13 \mathrm{GHz}$ to $16 \mathrm{GHz}$. There is a slight deviation in measured results as compared to the simulation which is mainly due to the SMA connector loss, measurement or fabrication errors. The measured results are in good agreement with the simulated results, except that there is slight frequency shift of approximately $1 \%$.

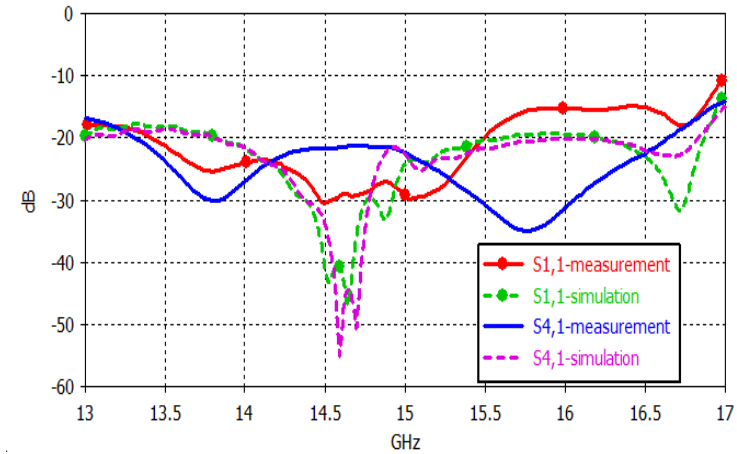

(a)

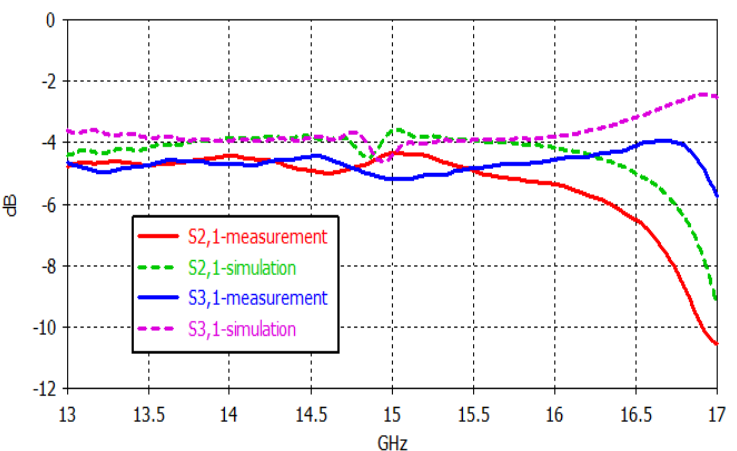

(b)

Figure 6. Comparison between simulation and measurement results of SIW hybrid coupler (a) $S_{11}, S_{41}$ (b) $S_{21}, S_{31}$.

\subsection{Simulation and Measurement Results of SIW Six-port}

The simulation and measurement results are shown in Figure 7. The simulated and measured reflection coefficient, $S_{11}$ and isolation, $S_{21}$ is lower than $-10 \mathrm{~dB}$ across 13.5 to $17 \mathrm{GHz}$ as seen in Figure 7(a), respectively. The simulated results of transmission coefficient, $\mathrm{S}_{31}, \mathrm{~S}_{41}, \mathrm{~S}_{51}$, and $\mathrm{S}_{61}$ are about $-7 \pm 1.5 \mathrm{~dB}$ across the operating frequency range of $13 \mathrm{GHz}$ to $16.5 \mathrm{GHz}$. The measured results of $\mathrm{S}_{31}$ is $-10 \pm 2 \mathrm{~dB}$ over $13 \mathrm{GHz}$ to $16.5 \mathrm{GHz}$ while for $S_{41}, S_{51}$, and $S_{61}$ are $-9 \pm 1 \mathrm{~dB}$ across the same frequency range as shown in Figure 7(b).

Figure 8 shows the phase difference between the different ports of the SIW six-port device within the frequency range of $13-16.5 \mathrm{GHz}$. The SIW six-port accomplished to achieve simulated phase difference between port 5 and port 6 of $90^{\circ} \pm 5^{\circ}$. 


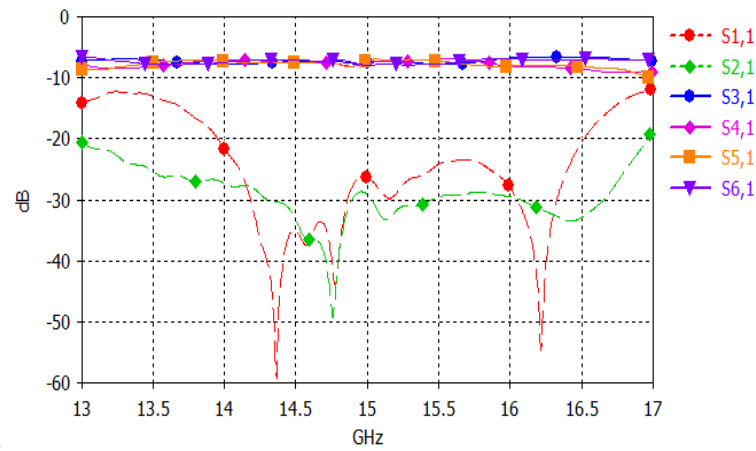

(a)

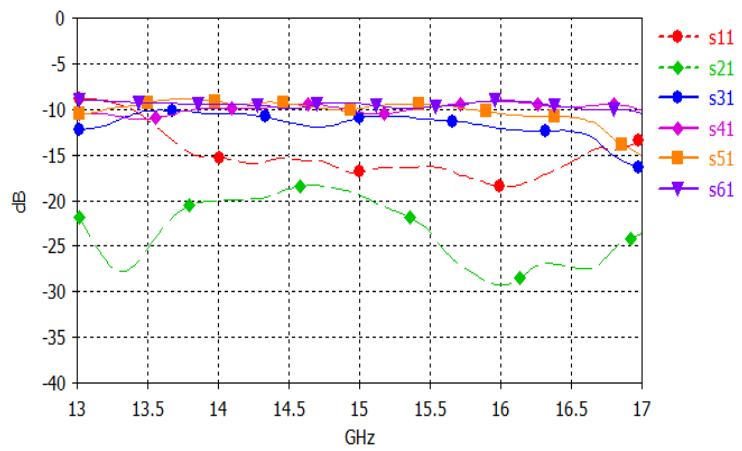

(b)

Figure 7. (a) Simulation and (b) Measurement results of SIW Six-port

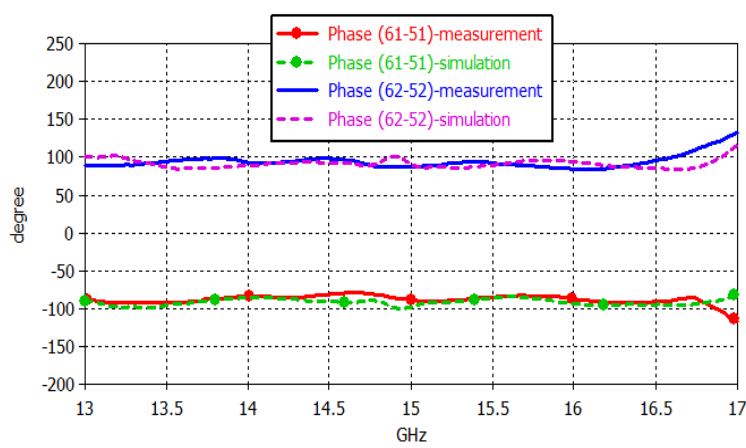

Figure 8. Comparison of simulation and measurement phase differences of SIW six-port

\section{CONCLUSION}

In this paper, a single layer Ku-band power divider, hybrid coupler, and six-port using SIW technology have been designed and fabricated. The chosen topology of the SIW six-port has no excessive ports. The simulated and measured results of the modified SIW hybrid coupler show that it has advantage of flat response of the coupling coefficient contributed by the modification of the position of a row of several vias at the centre of the side walls. The measurement results demonstrate that the combination of the Yjunction SIW power divider and the proposed SIW hybrid coupler can lead to design of SIW six-port operating in Ku-band. Good agreement between the measurements and simulations is obtained.

\section{ACKNOWLEDGEMENTS}

The author would like to acknowledge the support from the Fundamental Research Grant Scheme (FRGS) under a grant No. FRGS/1/2015/TK04/UNIMAP/02/16 from the Ministry of Higher Education Malaysia.

\section{REFERENCES}

[1] A. Koelpin, F. Lurz, S. Linz, S. Mann, C. Will and S. Lindner, "Six-port based interferometry for precise radar and sensing applications," Sensors, vol. 16, no. 10, pp. 1-26, 2016.

[2] G. Vinci, F. Barbon, R. Weigel and A. Koelpin, "A Novel, Wide Angle, High Resolution Direction-of-arrival Detector," in 2011 8th European Radar Conference, Manchester, 2011.

[3] F. Barbon, S. Lindner, S. Mann, S. Linz, R. Weigel and A. Koelpin, "Extended Range Distance Measurements Based on Frequency and Power Compensated Six-Port Receiver," in 2014 44th European Microwave Conference, Rome, 2014.

[4] G. Askari and M. Kamarei, "Design, Analysis and Implementation of Ultrahigh Data Rate UWB Six-Port Receiver Up to 7 Gbps for 5 G New Spectrum Radio Access and CAR," Progress In Electromagnetics Research, vol. 73, pp. 31-48, 2017.

[5] H. Li, J. Zhu and E. Li, "A Design of Compact Microwave Six-Port Device for Ultra-Wideband Applications," Progress In Electromagnetics Research, vol. 65, pp. 57-61, 2017. 
[6] S. A. Nordin, M. K. M. Salleh, Z. I. Khan, N. Ab Wahab, L. Noh and Z. M. Yusoff, "SIW Circular Cavity Single Mode Filter with Triangle Probe," Indonesian Journal of Electrical Engineering and Computer Science, vol. 11, no. 2, pp. 672-676, 2018.

[7] T. H. C. Bouazza, K. Nouri, J. Tao, B. S. Bouazza and T. H. Vuong, "Multilayer substrate integrated waveguide six-port circuit," Radioelectronics and Communications Systems, vol. 61, no. 2, pp. 64-71, 2018.

[8] K. Song, M. Fan and Y. Fan, "Wideband Half-Mode SIW Power Divider With Improved Output Isolation Using Slotline Isolation Technology," IEEE Access, 6, vol. 6, pp. 62029-62036, 2018.

[9] S. Karamzadeh, V. Rafiei and H. Saygin, "A new multi-functional half mode substrate integrated waveguide sixport microwave component," Progress In Electromagnetics Research, vol. 69, pp. 71-78, 2017.

[10] O. Kramer, T. Djerafi and K. Wu, "Dual-Layered Substrate-Integrated Waveguide Six-Port With Wideband Double-Stub Phase Shifter.," IET Microwaves, Antennas \& Propagation, vol. 6, no. 15, pp. 1704-1709, 2012.

[11] S. Lakhdhar, F. Harabi and A. Gharsallah, "A Novel SIW Six-Port Junction," in 2015 IEEE 15th Mediterranean Microwave Symposium (MMS), Lecce, 2015.

[12] M. Jafari, G. Moradi, R. S. Shirazai and R. Mirzavand, "Design and Implementation of A Six-Port Junction Based on Substrate Integrated Waveguide," Turkish Journal of Electrical Engineering \& Computer Sciences, vol. 25, no. 3, pp. 2547-2553, 2017.

[13] J. Chen, W. Hong, H. Tang, P. Yan, B. Liu and K. Wu, "A Millimeter Wave Six-Port Network Using Half-Mode Substrate Integrated Waveguide," Journal of Infrared, Millimeter, and Terahertz Waves, vol. 33, no. 3, pp. 348-356, 2012.

[14] X. Xu, R. G. Bosisio and K. Wu, "A New Six-Port Junction Based On Substrate Integrated Waveguide Technology," IEEE Transactions on Microwave Theory and Techniques, vol. 53, no. 7, pp. 2267-2273, 2005.

[15] F. Furqan, S. Attamimi, A. Adriansyah and M. Alaydrus, "Bandpass filter based on complementary split ring resonators at X-Band," Indonesian Journal of Electrical Engineering and Computer Science, vol. 13, no. 1, pp. 243-248, 2019.

[16] F. Xu and K. Wu, "Guided-Wave And Leakage Characteristics Of Substrate Integrated Waveguide," IEEE Transactions on Microwave Theory and Techniques, vol. 53, no. 1, pp. 66-73, 2005.

[17] M. N. Hafiz, M. H. Jamaluddin and R. Selvaraju, "A Cross Slot Coupling to Enhance Bandwidth of Dual-Layer SIW Structure," Indonesian Journal of Electrical Engineering and Computer Science, vol. 10, no. 2, pp. 617-622, 2018.

[18] Z. Yang, W. Chen, H. Lin, T. Yang and H. Jin, "A novel SIW power divider with good out-of-band rejection and isolation," IEICE Electronics Express, vol. 13, no. 8, pp. 1-6, 2016.

[19] G. S. Tan, S. Z. Ibrahim and M. S. Razalli, "24 GHz Substrate Integrated Waveguide Power Splitter For Six-Port Short Range Radar Based Sensor," in 2016 IEEE Asia-Pacific Conference on Applied Electromagnetics (APACE), Langkawi, 2016.

[20] B. H. Ahmad, S. S. Sabri and A. R. Othman, "Design of A Compact X-Band Substrate Integrated Waveguide Directional Coupler.," International Journal of Engineering \& Technology, vol. 5, no. 2, pp. 1905-1911, 2013.

[21] T. Castellano, O. Losito, L. Mescia, M. Chiapperino, G. Venanzoni, D. Mencareli, G. Angeloni, C. Renghini, P. Carta and F. Prudenzano, "Feasibility Investigation Of Low Cost Substrate Integrated Waveguide (SIW) Directional Couplers.," Progress In Electromagnetics Research, vol. 59, pp. 31-44, 2014.

[22] B. Rahali and M. Feham, "Design Of K-Band Substrate Integrated Waveguide Coupler, Circulator And Power Divider," International Journal of Information and Electronics Engineering, vol. 4, no. 1, pp. 47-53, 2014.

[23] A. Nasri, H. Zairi and A. Gharsallah, "Single Balanced Mixer Using Substrate Integrated Waveguide (Siw) $90^{\circ}$ Coupler.," International Journal of Engineering and Technology, vol. 8, no. 1, pp. 61-64, 2016.

[24] M. J. Tavakoli and A. R. Mallahzadeh, "Wideband Directional Coupler for Millimeter Wave Application based on Substrate Integrated Waveguide," Emerging Science Journal, vol. 2, no. 2, pp. 93-99, 2018.

[25] D. Deslandes, "Design Equations For Tapered Microstrip-To-Substrate Integrated Waveguide Transitions," in 2010 IEEE MTT-S International Microwave Symposium, Anaheim, 2010.

\section{BIOGRAPHIES OF AUTHORS )}

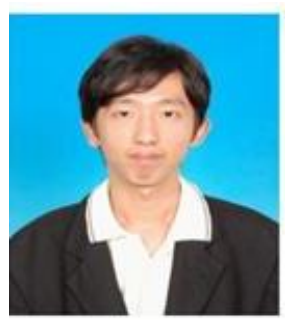

Tan Gan Siang received his Master of Science in Electronic Engineering from Universiti Teknikal Malaysia Melaka (UTeM), Malaysia, in 2015. He is currently working toward his $\mathrm{PhD}$ at School of Computer \& Communication Engineering, Universiti Malaysia Perlis, Malaysia. His research interests include microwave integrated circuits. 


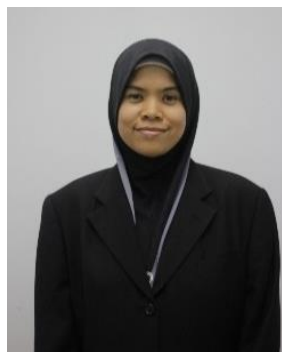

Dr. S. Z. Ibrahim was born in Limbang, Sarawak, Malaysia in 1981. She has a Bachelor of Engineering in Telecommunication from the University of Malaya, Malaysia in 2004 and Master of Engineering from University Technology of Malaysia in 2008. She received her $\mathrm{PhD}$ degrees from University of Queensland Australia in 2012. She is currently working as a senior lecturer in the School of Computer and Communication Engineering at Universiti Malaysia Perlis, Malaysia. Most of her research interest is related to microwave components and its application.

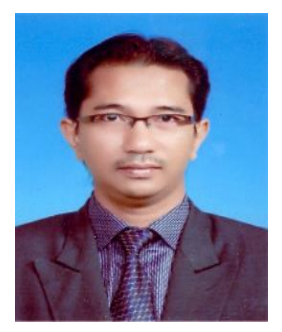

Ts. Dr Mohd Nazri A Karim is a Senior Lecturer at the Department of Electronic Engineering Technology, Faculty of Engineering Technology, Universiti Malaysia Perlis (UniMAP), Malaysia. He received his $\mathrm{PhD}$ in communication engineering from the School of Computer and Communication Engineering at Universiti Malaysia Perlis (UniMAP), Malaysia. His Master and Bachelor Degree in Electronics (Telecommunication) Engineering from Universiti Teknologi Malaysia (UTM), Malaysia in 2010 and 2006 respectively. He also a member of BEM, MBOT and IEEE Member. His research interests include antenna and propagation, microwave component and Radar technology especially in Ground Penetrating Radar (GPR).

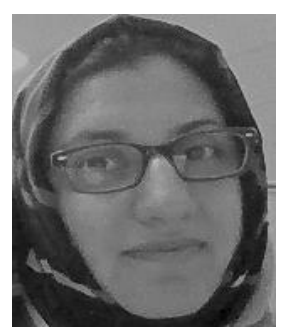

Dr. Aliya A. Dewani (M'12) received the B. Eng. degree (Gold Medalist) from the University of Kashmir, Srinagar, India, in 2005, the M. Eng. degree from University Technology Malaysia, Malaysia, in 2007, and the Ph.D. degree in electrical engineering from Griffith University, Brisbane, QLD, Australia, in 2016. Her doctoral research focused on the analysis and design of frequency selective surfaces on thin conformal transparent substrates using screen printing technology. She is currently a sessional lecturer with the Griffith School of Electrical engineering, Griffith University. Her current research interests include computational electromagnetics, design and modeling of engineered structures with novel electromagnetic behavior, multiple scattering, and antenna measurements.

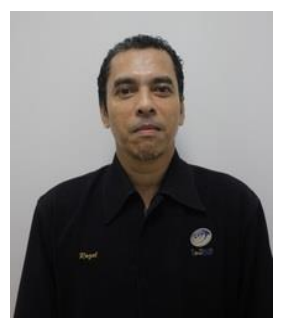

Dr. Mohammad Shahrazel Razalli is a Senior Lecturer at the School of Computer and Communication Engineering at Universiti Malaysia Perlis Universiti Malaysia Perlis (UniMAP), Malaysia. He received his PhD and M.Sc in Communications and Network Engineering at UPM. He had his Bachelor Degree in Electronics Engineering at University Of Leeds, United Kingdom. He received his B.Eng (Hons) in Electronic Diploma in Electrical (Electronic) Engineering, Institut Teknologi Mara. 